\title{
Modelling spatial variations in spawning habitat suitability for the sole Solea solea using regression quantiles and GIS procedures
}

\author{
Paul D. Eastwood ${ }^{1, *}$, Geoff J. Meaden ${ }^{1}$, Alain Grioche ${ }^{2}$ \\ ${ }^{1}$ Marine Fisheries GIS Unit, Department of Geography and Tourism, Canterbury Christ Church University College, \\ Canterbury, Kent CT1 1QU, United Kingdom \\ ${ }^{2}$ Laboratoire d'ichtyoécologie marine de l'Université du Littoral-Côte d'Opale, 17 avenue Blériot, BP 699, 62228 Calais, France
}

\begin{abstract}
In order to quantify spatial variations in spawning habitat suitability for the sole Solea solea (L.), spatial models were developed within a Geographical Information System (GIS) using data on the distribution of sole eggs within the eastern English Channel and southern North Sea, collected during March to June 1991. Raster maps of the physical environmental variables formed the basis of the models, with regression quantiles used to predict the spatial variation in sole egg density according to changes in physical habitat factors. The regression quantile parameter estimates were used to re-code the raster environmental maps so as to produce spatial models reflecting variations in both spawning activity and habitat suitability. Models developed for each month were then combined to produce a map of overall habitat suitability for a single spawning season. The use of regression quantiles allowed linear model parameters to be estimated for any part of the biological response, in this case sole egg density, including near to the upper bounds of the distribution. Changes near to the upper bounds would be expected when habitat factors included in the model actively limit the biological response, with the variation below the maxima caused by the influence of unmeasured factors. Spatial models developed using regression quantiles therefore yield predictions of the upper limits imposed by the measured habitat factors, i.e. the potential biological response. Spatial variations in sole egg density were found to be limited by depth, temperature, salinity and sediment type, with highest densities found in the shallower regions over sediments consisting of $<30 \%$ gravel. The final models predicted different scores of spawning habitat suitability at each spatial location, with the model developed from upper regression quantiles generally predicting higher suitability scores. Models performed well when tested with data describing the distribution of sole eggs along the French coast of the eastern English Channel in April 1995. The use of regression quantiles allowed for the development of spawning habitat models that portrayed the upper limits imposed by the measured habitat factors. Underestimation of the relative importance of the habitat in terms of its suitability for spawning was therefore minimised using this technique.
\end{abstract}

KEY WORDS: Habitat suitability models · Solea solea $\cdot$ Regression quantiles $\cdot$ Eastern English Channel • Southern North Sea · Geographical Information Systems

Resale or republication not permitted without written consent of the publisher

\section{INTRODUCTION}

Habitat degradation and destruction has long been recognised as a major contributing factor to the decline of fish populations. Indeed, with the exception of con-

*E-mail: p.d.eastwood@cant.ac.uk tinued unrestrained fisheries exploitation, Hall (1998) describes habitat destruction as 'arguably the single most effective way of slowing or preventing stock recoveries'. More than ever, there appears to be general agreement amongst fisheries management practitioners of the need to adopt ecosystem concepts into management plans (Tegner \& Dayton 1999), within 
which habitat description and definition forms an integral part (NMFS 1999).

In the US, large-scale efforts are underway to gather information on the habitat requirements of fish at various stages in their life history, and this has highlighted the lack of knowledge concerning the habitat needs of many fish species (Schmidt 1998). Basic information on the spatial extents of the underlying variables that influence the spatial and temporal distribution of fish populations are also required. Important abiotic habitat descriptors for demersal marine fish, such as temperature, depth and sediment type (e.g. Scott 1982, Murawski \& Finn 1988, D'Amours 1993, Swain \& Kramer 1995, Norcross et al. 1999), are often collected routinely during fisheries surveys and are relatively straightforward to map within most modern Geographical Information Systems (GIS). In contrast, biotic variables such as prey availability and benthic structural complexity, which also contribute to habitat definition (Kaiser et al. 1999), are often not sampled routinely, and so are frequently excluded from habitat models and definitions purely because of a lack of data (Brown et al. 2000). For models of habitat suitability that use changes in fish density as a proxy, with increasing density indicating increasing habitat suitability, a certain amount of spatial variability is therefore often left 'unexplained'. The amount of unexplained variability can usually be reduced by including a greater number of variables in the model although with models developed from field data, it would be unlikely that all relevant variables can be included (Thomson et al. 1996), assuming that they are even known and are measurable.

Using available information on fish-habitat relationships, methods to define and delineate fish habitat were first developed by the US Fish and Wildlife Service in the form of Habitat Suitability Index (HSI) models (USFWS 1980). The models were based on the hypothesis that the quality of a location to a species could be determined if the biological response of the species to the range of environmental variables measured at that location were known. As an initial stage, the biological response to various environmental variables was estimated. Individual responses were then converted into an index of suitability by scaling the predicted response from 0 to 1 . Any number of suitability indices could then be combined to yield an overall description of habitat suitability. For many of the original HSI models, the suitability indices were constructed primarily from published information on species-habitat relationships, and supplemented by expert review. Recent attempts have been directed at developing models within a GIS environment, using both published information (Christensen et al. 1997, Brown et al. 2000) and empirical data (Clark et al. 1999,
Rubec et al. 1999). Models developed in this way offer immediate advantages over previous models in that the spatial limits and areal extent of various habitat suitability classes are easily mapped and quantified.

Clearly an important consideration with respect to HSI models is the way in which the biological response to each environmental variable is estimated. Where this is achieved by fitting 'least-squares' regression models to empirical data, the relationship described by the parameter estimates is that of the mean response. Thomson et al. (1996) argued against such an approach as conflicting with the ecological concept of limiting factors, noting that simple least-squares regression would only be able to describe the relationship if all other potentially limiting factors were known and held constant. In this scenario, a scatterplot of a species response to a measured habitat variable would produce an easily identifiable linear response. As noted earlier, the more common situation, however, is of a response distribution, such as fish density, characterised by a high degree of variability with only a certain proportion being accounted for by some known variables. In other words, the species response is dependent on a range of variables both measured and unmeasured, including history and chance (Thomson et al. 1996). A scatterplot in this more common scenario would show a point cloud defined by an upper ceiling. Rather than modelling changes through the centre of the data distribution, changes near the upper bounds might provide a better estimate of the changes expected when the measured habitat factor is actively limiting the response. Moreover, least-squares modelling techniques that estimate changes through the centre of the response will consistently underestimate the potential response to the habitat factors considered in the model, and provide only the general direction and shape of the response. A number of methodologies have been explored that are capable of describing the upper bounds of scatterplots, and include partitioned regression (Thomson et al. 1996) and regression quantiles (Terrell et al. 1996, Cade et al. 1999). Whilst still in the developmental stage, Terrell \& Carpenter (1997) call for the use of such techniques to improve the efficacy of HSI models.

Within the eastern English Channel and southern North Sea, sole have been found to spawn predominantly within inshore waters and over offshore sandbanks at depths of <30 m (Borremans 1987, Land 1991, ICES 1992, Grioche 1998). The entire range of variables that may quantitatively define and describe sole spawning habitat are unknown, and models generally need to rely on a few measured abiotic factors. Regression quantiles can potentially provide better estimates of the limits to spawning activity imposed by the measured habitat variables, and in doing so minimise 
underestimation of the relative importance of the habitat in terms of its suitability. The objectives of the study were therefore 3-fold. Firstly, to define and delineate sole spawning habitat by developing an empirical habitat suitability model within a GIS environment. Secondly, to compare a model developed from central estimates with one based on estimates of the upper bounds of the response through the use of regression quantiles, as described by Terrell et al. (1996) and Cade et al. (1999). And thirdly, to evaluate the predictive power of the final models of spawning habitat suitability by using an independent dataset describing the distribution of sole eggs within the study area.

\section{MATERIALS AND METHODS}

Survey data. Two sources of data were available that described the temporal and spatial distribution of sole eggs within the eastern English Channel and southern North Sea. The first was derived from surveys conducted by the UK Centre for Environment, Fisheries and Aquaculture Science (CEFAS) in March, April, May and June 1991, and which formed part of an internationally co-ordinated survey covering the eastern and western English Channel and southern North Sea. Survey stations were located on a spatial grid corresponding to ICES grid squares and subdivisions thereof, and both the number of stations and the spatial coverage varied during each month (Fig. 1). The second source of data was derived from ichthyoplankton surveys conducted in April and May 1995 along the French coast of the eastern English Channel, the results of which are described by Grioche et al. (1999). As the survey covered a more restricted area and sole eggs were only counted during April 1995, this data was retained for model testing, with the 1991 CEFAS survey data used for model development.

For the 1991 CEFAS survey, eggs were sampled using a modified Gulf III sampler of $50 \mathrm{~cm}$ internal diameter with a 19/20 cm diameter nose cone and $420 \mu \mathrm{m}$ mesh plankton net. Samples consisted of 1 or more double oblique hauls from the surface to as close to the bottom as possible at a standard towing speed of 5 knots. Station positions were recorded at the start of each tow, with the intention of being in the cen- tre of each ICES grid square at the bottom of a Vshaped profile, i.e. surface-bottom-surface (S. Milligan, CEFAS, pers. comm.). The rate of descent and ascent was maintained at ca $0.1 \mathrm{~m} \mathrm{~s}^{-1}$. Once collected, samples were fixed and preserved in $4 \%$ formaldehyde solution before being sorted and staged. Egg stage was determined according to the scheme of Riley (1974), with eggs classified into 1 of 5 stages ranging from 1a to 4 , and final results expressed as numbers of each stage per $\mathrm{m}^{2}$. Stage 1a sole eggs were taken as representative of the location of spawning adults, being at most $2 \mathrm{~d}$ old in ambient water temperatures of $7^{\circ} \mathrm{C}$ (Riley 1974). Temperature and salinity profiles were also taken at each station. A detailed description of the sampling methodology adopted for other regions of the co-ordinated survey is given in ICES (1992).

Chart depth and sediment type at each survey location were obtained directly from the latest available charts and maps developed by the UK Hydrographic Office (UKHO) and the British Geological Survey (BGS). Digital raster maps of both bathymetry and sediment type for the study region, developed as part of this study for the sea area between 50 to $52^{\circ} \mathrm{N}$ and 0 to $3^{\circ} \mathrm{E}$, allowed data at each station to be extracted
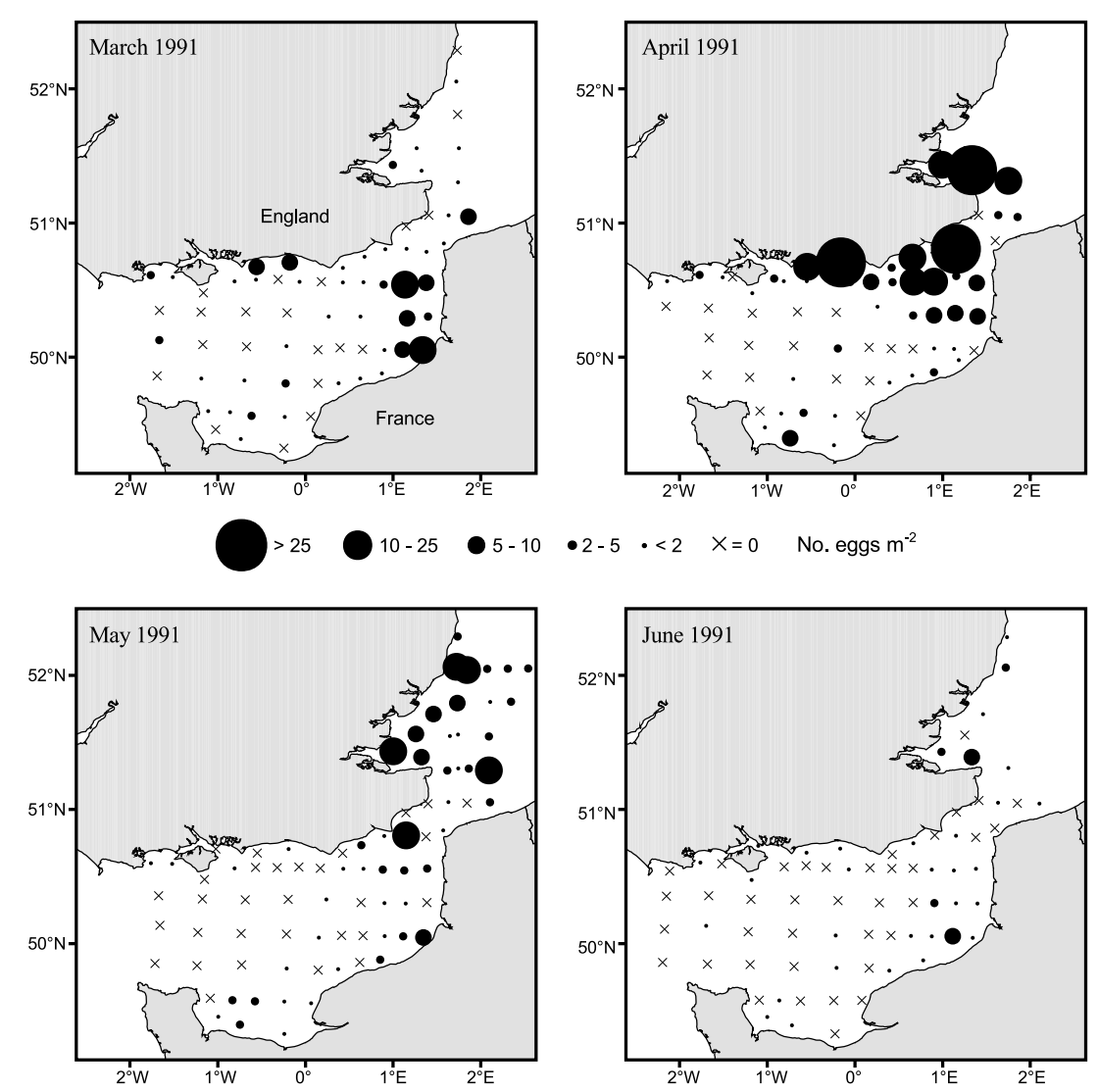

Fig. 1. Distribution of Stage 1a sole eggs in the eastern English Channel and southern North Sea from March to June 1991 
from directly within the GIS. Depths at survey stations falling outside of this region were obtained from adjoining paper charts. Where possible, BGS paper maps were used to provide information on the sediment type at other survey stations, although the coverage was incomplete. Sediment type was represented as 1 of 15 sediment classes based on Folk (1954), or of 3 classes located along the French coast of the eastern Channel, generalised by the BGS from 'Les sediments superficiels de la Manche', published in 1979 by the Bureau de Récherches Géologiques et Minières (BRGM), the Centre National pour l'Exploration des Océans (CNEXO) and the Service Géologique National (SGN).

Estimation of limiting factors. The approach taken to develop models of limiting factors for spawning sole was dependent on the type of data representing the habitat variables. For depth, temperature and salinity, measured on a continuous scale, monthly estimates of changes in Stage 1a sole egg density were made using regression quantiles. For sediment type, represented as categorical data, the difference between Stage 1a egg density associated with each sediment type was examined.

Regression quantiles are the linear model equivalent of 1-sample quantiles in that they allow data distributions to be split into quantile classes, such as the 25th, 50th, 75th, 90th etc. One-sample quantiles are extended to regression by minimising a function of absolute deviations, as opposed to least-squares regression which minimises a function of squared deviations (i.e. the sum of squares). The 50th regression quantile is equivalent to a least absolute deviation (LAD) regression where $50 \%$ of the observations are less than and $50 \%$ are greater than the fitted line. LAD regression therefore estimates the conditional median in a linear model, as opposed to ordinary least-squares regression which estimates conditional means. Any quantile can be estimated conditional on the linear model $\mathbf{y}=\boldsymbol{\beta} \mathbf{x}+$ $v(\mathbf{x}) \mathbf{e}$, where $\mathbf{y}$ is a vector of $n \times 1$ dependent responses (e.g. sole egg density), $\boldsymbol{\beta}$ is a vector of $p \times 1$ unknown regression parameters, $\mathbf{x}$ is a matrix of $n \times p$ predictors, and $\mathbf{e}$ is a vector of $n \times 1$ random errors that are independent and identically distributed (Koenker \& Bassett 1978). The term $v(\mathbf{x})$ allows the errors to change as a function of $\mathbf{x}$ and thus both homoscedastic and heteroscedastic error models are accommodated.

A range of regression quantiles were examined (e.g. 10th, 25th, 50th, 75th, 80th, 85th, 90th, 95th and 99th) in order to determine a model of best fit for both central (50th) and upper quantiles. An initial investigation found that parameter estimates based on $\log _{\mathrm{e}}(y+1)$ transformed Stage 1a egg data gave a better fit to the data points. Regression quantile models were therefore developed for transformed data and subsequently back-transformed into the original scale. In contrast to least-squares estimates of the mean, regression quantile estimates do not suffer from bias when back-transforming into the original scale when using non-linear, monotonic transformations, such as log transformations (Cade et al. 1999). The 3 variables of depth, temperature and salinity were initially included in each quantile model, with the best set of predictors chosen through backwards elimination. The significance of each variable was determined through hypothesis testing of the full model against a reduced model where the parameter being tested was constrained to 0 . The probability level at which a variable was removed from the model was set at 0.05 . The testing procedure used an asymptotic rank-score test statistic developed by Koenker \& d'Orey (1994), with probabilities evaluated as $\chi^{2}$ distributed with the appropriate degrees of freedom ( 1 for each parameter being tested). Once the predictors had been selected, all first order interactions were included and again tested for significance through the construction of hypothesis tests. Estimates were arrived at for both central (50th) models and the highest quantile model with significant slope coefficients, in order to provide the best estimate of changes in egg density at the upper limits of the distribution. The computer program BLOSSOM (Cade \& Richards 2000) was used throughout this study to develop regression quantile estimates and construct hypothesis tests ${ }^{1}$. The reader is referred to Cade et al. (1999) and Cade \& Richards (2000) for a more detailed description of the statistical theory of both regression quantiles and the rank-score test implemented within the BLOSSOM program.

As sediment type data was only available for approximately $2 / 3$ of the survey stations, and as the data was represented by 2 different classification systems, a separate approach had to be taken to determine whether the distribution of sole eggs was related to sediment type. Using the available data, the difference in sole egg density $\left(\log _{\mathrm{e}}(y+1)\right.$ transformed) between the sediment types was examined. As each type was associated with a limited number of observations of egg density, sediment types were first aggregating into 4 classes. These were $>80 \%$ gravel, between 30 and $80 \%$ gravel, between 5 and $30 \%$ gravel, and $<5 \%$ gravel. Percentage content of gravel was used to aggregate the sediment types, as opposed to sand or mud, as it was common to both classification systems represented on the BGS maps.

A major drawback of the above method is that by modelling the response to sediment type separately from that of the 3 continuous variables of depth, tem-

\footnotetext{
${ }^{1}$ Available from the USGS Midcontinent Ecological Science Centre: http://www.mesc.usgs.gov/blossom/blossom.html
} 
perature and sediment type, the 2 modelled responses are assumed to be independent of each other. Clearly a more realistic approach would be to incorporate sediment type within the regression models as an indicator variable. In any type of regression analysis an indicator variable can be used to include information from categorical data into a regression model (Montgomery \& Peck 1992). Individual classes of the categorical variable are coded with an integer, typically 0 and 1 . For example, if the categorical variable has 2 classes, then the indicator variable would be assigned either a 0 or 1 , depending on which class the data point was associated with. The set of $0 \mathrm{~s}$ and $1 \mathrm{~s}$ becomes an additional variable in the regression model, with parameters for the indicator variable tested for significance in the same way as for continuous variables. What is being tested is whether the categorical variable leads to a significant difference between the intercept of the 2 regression models, one of which is fitted to the data associated with the one class of the categorical data, with the other model fitted to data in the second class. Differences in slope estimates can also be tested by including as an additional variable the cross-product(s) between the indicator variable and the continuous variable(s) in the model. An initial investigation determined that too few sediment type data were available to allow parameters to be estimated for individual months. Therefore data for all 4 months were combined into a single dataset. Central and upper regression quantile models were developed using the backwards elimination procedure described above, but now including sediment type as an indicator variable.

Development of digital environmental maps. Digital raster maps, or layers, were created within the GIS (ArcInfo 7.2.1, Environmental Systems Research Institute, USA) for bathymetry, sediment type, mean water column temperature, and mean water column salinity. To develop each raster layer, the raw data had to be entered initially into the GIS either as a series of vector points, polylines or polygons, depending on the data type, and referenced to the same underlying co-ordinate system. The vector data were then converted into raster format using the techniques described below. Raster data formats facilitate spatial modelling by allowing new raster layers to be calculated based on the values of the spatially-coincident cells within the input layers. Here, the input layers were the environmental variables; the output layers were the habitat suitability maps.

To create a bathymetric raster map, contours and spot depths were digitised as a series of points and vector polylines from the most recently published UKHO charts for the study region. Interpolation of the vector data into a raster layer of continuously varying depth was achieved using a modification of a discretised thin plate spline routine, and implemented in ArcInfo, which permits the fitted model to follow abrupt changes in terrain. The quality of the interpolation procedure was evaluated by withholding $2 \%$ of the data points from a subset of the data, and calculating the root mean square (RMS) error of the difference between the original data points and the interpolated, spatially coincident raster cells. A cell size of $200 \mathrm{~m}^{2}$ was chosen for the final raster map.

Monthly temperature and salinity values from the 1991 sole egg survey were digitised and represented in the GIS as a series of vector point layers. Interpolated raster layers were produced using minimumcurvature splines to ensure the output surface conformed to the input points with a minimum of error. Other exact interpolation techniques were explored (e.g. kriging) and were found to produce similar results, with the final selected technique based on the lowest RMS error obtained using a similar methodology to that described above. Output raster layers of $200 \mathrm{~m}^{2}$ cell size, representing mean water column temperature and salinity, were produced for each month.

A digital map of the sea-bed sediments was developed from the most recently published BGS 1:250 000 scale paper maps, by digitising sediment regions as a series of contiguous vector polygons. Additional secondary qualitative sources of information were used to complete areas of the map where data were missing. These areas were principally close to the UK coastline and on the eastern side of the Dover Straits. Data for a large region of the Belgian coastal zone were also missing, and as no secondary sources of information were available, the region was broadly classified according to the predominant sediment type found within the surrounding area, namely sand containing $<30 \%$ gravel. The final sediment map was converted from the vector polygons into a raster layer of $200 \mathrm{~m}^{2}$ cell size, with each cell holding the relevant sediment code in its attribute table.

Habitat suitability models. A diagrammatic summary of the methodologies employed to develop the habitat models is given in Fig. 2. Method A is described first and relates to the method whereby separate regression quantile models were developed for each month. Considering each month individually, in Step 1 of Method A, parameter estimates from the highest significant regression quantile were used to re-code the cells in the relevant environmental raster maps. This produced a single prediction surface of sole egg density for each month representative of the regression quantile model. The sediment type raster layer was also re-coded using the 95th percentile of sole egg density determined for each sediment class, which again produced a single prediction map for each month. The final habitat suitability map for each month was then calculated as the geo- 

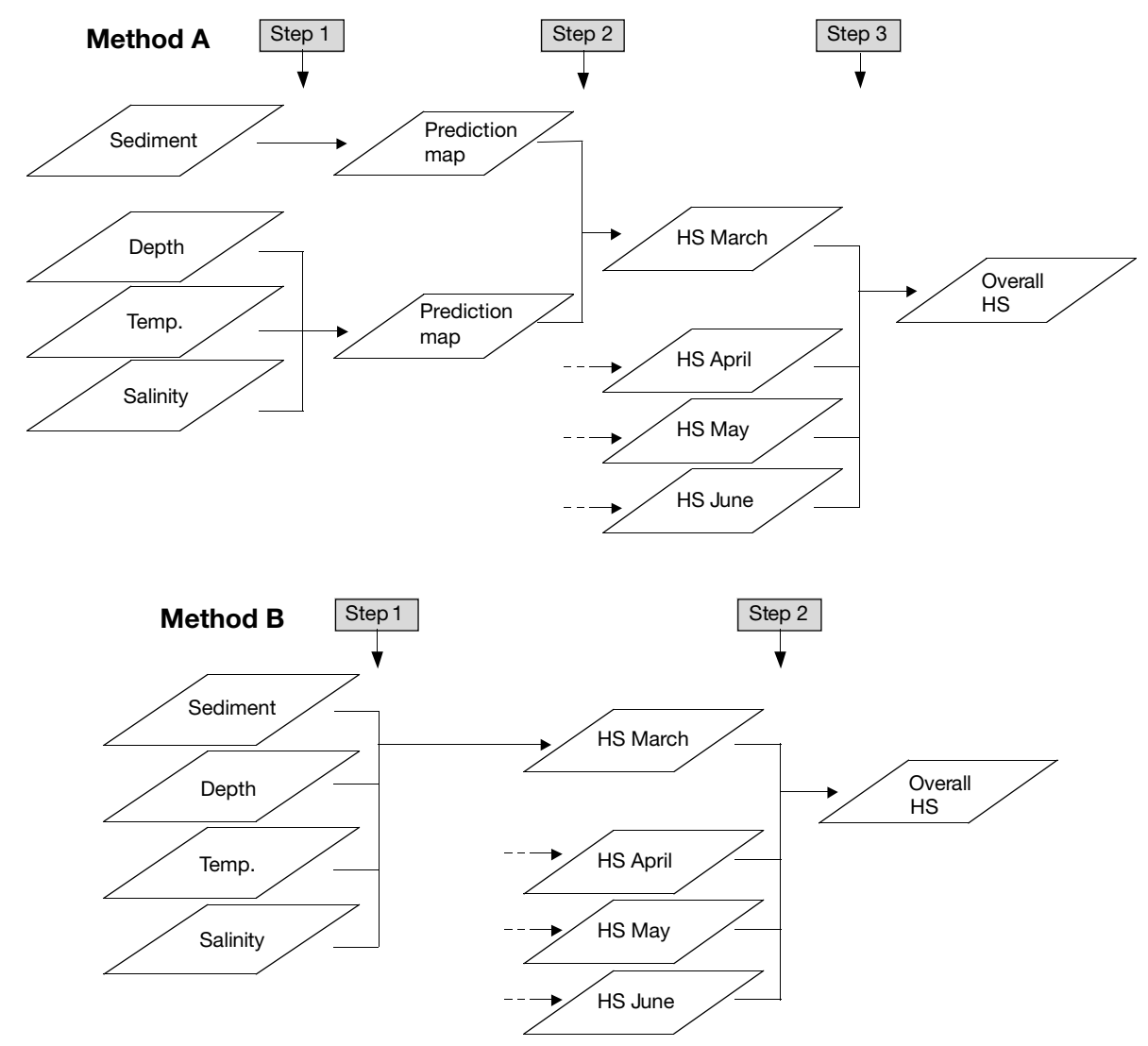

Fig. 2. Diagrammatic representation of the modelling procedure. Method A: Step 1; all relevant raster maps of depth, temperature and salinity are re-coded using the regression quantile coefficients, and the sediment map is re-coded with the density percentiles for each sediment class. Step 2; the geometric mean is calculated for each spatially coincident grid cell in the 2 prediction maps to produce a prediction map of habitat suitability (HS) for each month. Step 3 ; the output prediction maps are converted to a relative scale $(0-1)$ and the arithmetic mean of each spatiallycoincident cell in the HS maps is calculated to produce an overall habitat suitability map. Method B: Step 1; all relevant digital environmental maps are re-coded using the regression quantile coefficients. Step 2; same as Method A Step 3 sponse, with one based on the equivalent upper estimates, the entire process was repeated using the monthly prediction models developed from the central (50th) regression quantile parameter estimates and median sole egg density within each sediment class. The process was also repeated for the central and upper regression quantile estimates that were developed when data from all 4 months were combined, and where sediment type was included as an indicator variable. Here, the methodology was simplified, as Step 2 of Method A was no longer needed as only 1 prediction map was developed for each month. The methodology used to construct the second set of habitat models based on all data combined is shown diagrammatically in Fig. 2, where it is referred to as Method B.

To simplify visualisation, the final habitat models were re-classified into maps consisting of 4 classes ranging from 0 (unsuitable habitat) to 1 (optimal habitat). These were: 0 to $0.25,0.25$ to $0.5,0.5$ to 0.75 , and 0.75 to 1.0 . The ability of the final habitat models to predict changes in sole egg density as a factor of spawning habitat suitability was evaluated using data on the spatial distribution of sole eggs along the French coast of the eastern English Channel, collected during April 1995. Ichthyoplankton were sammetric mean of spatially coincident cells in the 2 input prediction maps (Step 2 of Method A). The geometric mean is commonly used to ensure that regions considered unsuitable in relation to 1 or more variables are classified as 0 regardless of the suitability at that location of other variables in the model (Brown et al. 2000). To produce an overall habitat suitability map for the entire spawning season, the 4 monthly sole egg prediction models were initially scaled from 0 to 1 to ensure that each month was given equal weighting in terms of the relative importance of the habitat. The final habitat model was then calculated as the arithmetic mean of spatially coincident cells for the 4 monthly raster layers of predicted relative sole egg density (Step 3 of Method A).

In order to assess potential differences between a model based on central estimates of the species re- pled with a Bongo net fitted with two $500 \mu \mathrm{m}$ mesh size nets. At each station the nets were towed obliquely from the surface to the bottom of the water column at a speed of 2 knots. Samples were fixed in a $5 \%$ formaldehyde seawater solution before being sorted and staged. Sole eggs collected during this survey were classified into 2 stages, with early stage eggs corresponding to Stages 1 and 2 of the classification scheme given by Riley (1974), and late stage eggs corresponding to Stages 3 and 4 . The early stage eggs from the April 1995 survey were therefore broadly comparable to the Stage 1a eggs from the 1991 surveys. Correlations between the density of early stage eggs in April 1995 and suitability scores from the habitat models were computed, and a series of regression quantiles fitted to compare the observed distribution in the test data with that predicted by the models. 


\section{RESULTS}

The spatial distribution and density of Stage 1a sole eggs from March to June 1991 is shown in Fig. 1 with a summary of the results used to develop the regression quantile models given in Table 1 . Of the 4 months, egg density was generally highest in April, and then decreased through May and June. Within each month egg densities were generally highest within the more inshore regions along the French and English coasts. Taken over the entire survey area, the mean water column temperature gradually rose from $7.7^{\circ} \mathrm{C}$ in March up to $11.3^{\circ} \mathrm{C}$ in June, whilst the mean water column salinity remained relatively constant.

The regression quantile models developed for each month are described in Table 2 and shown in Fig. 3. For all 4 months the 10th quantile was associated with the 0 values and could not be estimated, with the 25th quantiles also associated with the 0 values in March and June. In March both temperature and depth were significant for quantiles greater than the 50th $(\mathrm{p}<0.05$ for all quantiles) with a significant interaction found between depth and temperature for the 50th and 94th quantiles $(p<0.05)$. The 94th quantile therefore gave

Table 1. Mean number $( \pm$ SE) of Stage 1a sole eggs during March to June 1991, and associated physical variables. The location of survey points is shown in Fig. 1

\begin{tabular}{|lccccc|}
\hline & $\mathrm{n}$ & $\begin{array}{c}\text { No. of } \\
\text { eggs m }\end{array}$ & $\begin{array}{c}\text { Water column } \\
\text { temperature }\left({ }^{\circ} \mathrm{C}\right)\end{array}$ & $\begin{array}{c}\text { Water column } \\
\text { salinity (psu) }\end{array}$ & Chart depth (m) \\
\hline March & 67 & $1.6(0.36)$ & $7.69(0.064)$ & $34.97(0.068)$ & $29.9(1.69)$ \\
April & 69 & $4.7(1.22)$ & $8.85(0.041)$ & $35.03(0.060)$ & $30.0(1.63)$ \\
May & 83 & $2.2(0.39)$ & $9.91(0.057)$ & $34.81(0.057)$ & $29.8(1.41)$ \\
June & 71 & $0.6(0.16)$ & $11.31(0.077)$ & $34.85(0.062)^{\mathrm{a}}$ & $30.1(1.67)$ \\
\multicolumn{4}{l}{ a Salinity mean and standard error for June based on 67 points due to missing data } \\
\hline
\end{tabular}

Table 2. Parameter estimates and associated significance from rank score tests for central and upper regression quantile models of best fit, for changes in sole egg density (no. $\mathrm{m}^{-2}, \log _{\mathrm{e}}(y+1)$ transformed) according to temperature $\left({ }^{\circ} \mathrm{C}\right)$, salinity (psu), and depth (m). Models are based on data from March, April, May and June 1991. $\mathrm{T} \times \mathrm{D}$ is temperature-depth interaction and $\mathrm{T} \times \mathrm{S}$ is temperature-salinity interaction. Significance of the whole model is also given where appropriate. ${ }^{*} \mathrm{p}<0.05,{ }^{* *} \mathrm{p}<0.01,{ }^{* * *} \mathrm{p}<0.001$

\begin{tabular}{|c|c|c|c|c|c|c|c|c|}
\hline \multicolumn{2}{|c|}{ Quantile } & \multirow{2}{*}{$\begin{array}{c}\text { Constant } \\
-5.225\end{array}$} & $\begin{array}{l}\text { Temp. } \\
1.020^{*}\end{array}$ & $\begin{array}{c}\text { Depth } \\
-0.0004^{*}\end{array}$ & \multirow{2}{*}{ Salinity } & $\begin{array}{c}\mathrm{T} \times \mathrm{D} \\
-0.004^{*}\end{array}$ & \multirow{2}{*}{$\mathrm{T} \times \mathrm{S}$} & \multirow{2}{*}{$\begin{array}{c}\text { Whole } \\
\text { model } \\
*\end{array}$} \\
\hline March & $\begin{array}{l}94 \\
50\end{array}$ & & $\begin{array}{l}1.020^{*} \\
0.789^{* *}\end{array}$ & $\begin{array}{c}-0.0004^{*} \\
0.084^{*}\end{array}$ & & $\begin{array}{l}-0.004^{*} \\
-0.014^{*}\end{array}$ & & \\
\hline April & 79 & -33.816 & & $-0.046^{*}$ & $1.051^{*}$ & & & * \\
\hline May & $\begin{array}{l}88 \\
50\end{array}$ & $\begin{array}{r}-76.980 \\
8.367\end{array}$ & $\begin{array}{l}10.550^{* *} \\
-0.685^{*}\end{array}$ & $-0.030^{* *}$ & $2.386^{* * *}$ & & $-0.316^{*}$ & $\begin{array}{l}* * * \\
* *\end{array}$ \\
\hline June & $\begin{array}{l}87 \\
50\end{array}$ & $\begin{array}{l}2.406 \\
0.373\end{array}$ & $-0.069^{*}$ & $\begin{array}{r}0.099^{* *} \\
-0.007^{* *}\end{array}$ & & $-0.012^{* *}$ & & $* *$ \\
\hline
\end{tabular}

the best estimate of changes expected in the density of sole eggs when both depth and temperature were the active limiting factors. Egg density was found to be higher within the warmer, shallower regions of the eastern English Channel and southern North Sea, with the 50th and 94th regression quantile models predicting a positive density of eggs at temperatures above 6.35 and $5.35^{\circ} \mathrm{C}$ respectively at a depth of $10 \mathrm{~m}$ below chat datum. In April, depth and salinity were found to (t) 79 th quantiles $(p<0.05)$ the shallow water regions, and also with increasing salinity.

In May, temperature and salinity were found to produce the model of best fit for a limited range of upper quantiles (84th to 88th), with the interaction between salinity, with the same response predicted over the entire range of temperatures. In contrast the response to temperature was partly dependant on the salinity. At the higher end of the salinity range, egg density was predicted to decrease with temperature, with the converse true at the lower end of the salinity range. Temperature and depth yielded the model of best fit based on central estimates, with a negative relationship found between egg density and both temperature and depth. In June, temperature and depth were also found to produce the model of best fit for a few upper quantiles (80th to 87 th), with the 87 th quantile the highest where both terms were significant, along with the interaction between temperature and depth. The predicted response was the same as for the May 50th model, with egg density decreasing with both temperature and depth. For the June central model, depth alone proved to be a significant predictor $(p<0.01)$, with egg density decreasing with depth, similar to all other models where depth was included as a significant explanatory variable.

An overall significant difference was found between the density of sole eggs associated with the 4 sedi- 
March $199150^{\text {th }}$ and $94^{\text {th }}$ regression

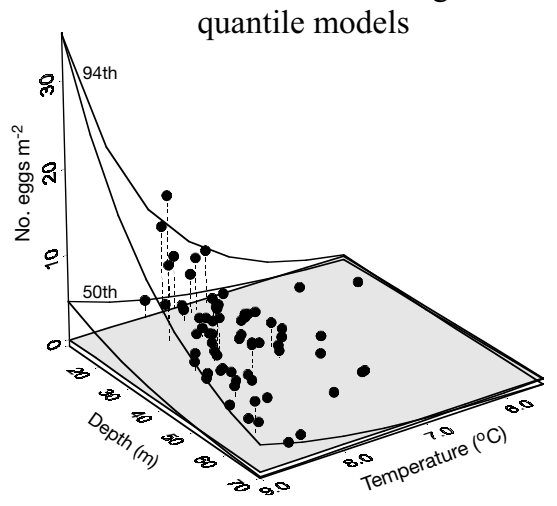

May $199188^{\text {th }}$ regression quantile model

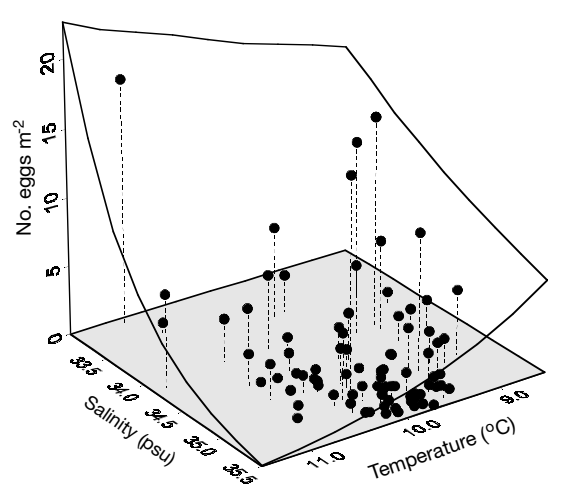

June $199187^{\text {th }}$ regression quantile model

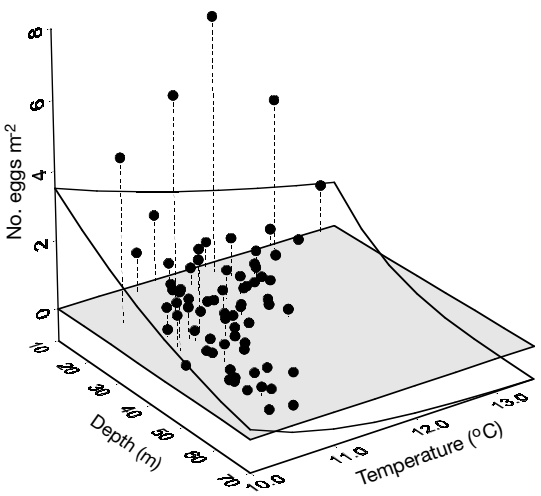

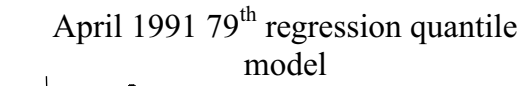

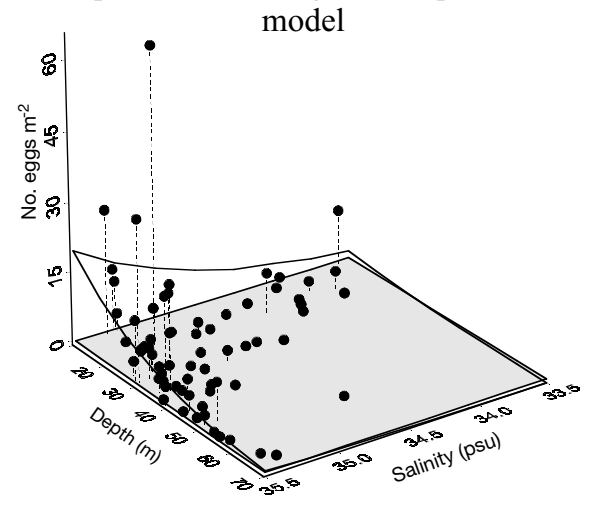

May $199150^{\text {th }}$ regression quantile model

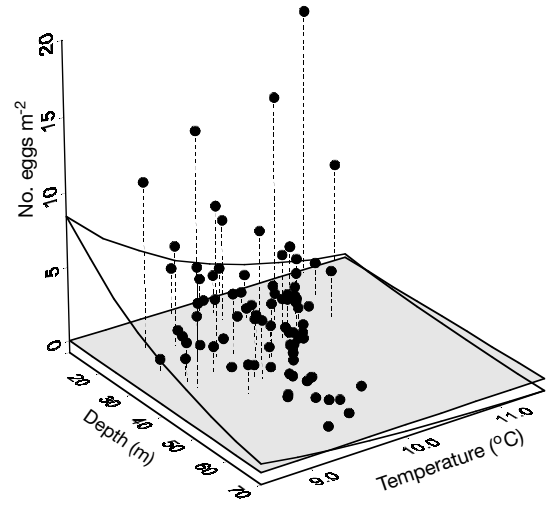

June $199150^{\text {th }}$ regression quantile model

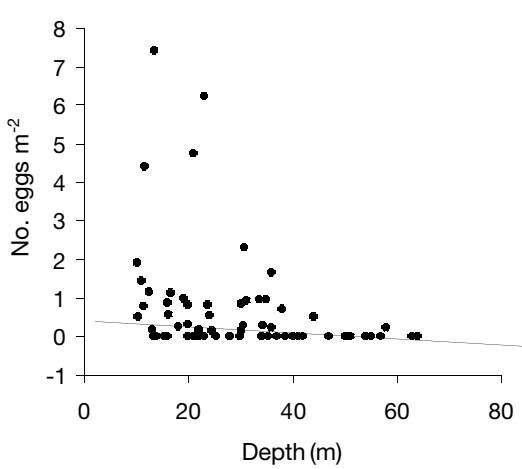

Fig. 3. Scatterplots of Stage 1a sole egg density and fitted regression quantile models based on parameter estimates given in Table 2 for March, April, May and June 1991. Zero egg density is depicted by the shaded plane

ment classes (Kruskal-Wallis, $\mathrm{p}<0.05$ for all 4 months), but not between all individual classes. As a result the classes were further aggregated based on the least significant differences in sole egg density between the previous 4 classes. The 2 final sediment classes were $>30 \%$ and $<30 \%$ gravel (Fig. 4). A significant difference in egg density between the 2 sediment classes was found during all 4 months (March, Mood's $\chi_{(1)}^{2}=20.84, \mathrm{p}<0.001$; April, Mann-Whitney $W=446, \mathrm{p}<$ 0.001; May, Mann-Whitney $W=$ 567, $\mathrm{p}<0.001$; June, Mann-Whitney $W=439.5, \mathrm{p}<0.001$ ), with a higher density associated with sediments containing $<30 \%$ gravel (Table 3). Median and 95th percentiles of egg density for the 2 final sediment classes within each month were used as input to the habitat models, with the 95th percentile used as an estimate of the upper limit of sole egg density within each sediment class.

The scatterplots shown in Fig. 3 clearly show the degree to which the variables within each month were intercorrelated. Indeed, all possible correlations between temperature, salinity and depth were found to be significant (Spearman's rank correlation, $\mathrm{p}<0.05$ ), with the exception of salinity and temperature in April $(\mathrm{r}=0.212, \mathrm{p}>$ $0.05)$, and salinity and temperature in May $(r=0.109, p>0.05)$. A similar situation was encountered when the data from all 4 months were combined, with highly significant correlations found between salinity and temperature $(\mathrm{r}=0.316, \mathrm{p}<0.001)$, and salinity and depth $(\mathrm{r}=0.554, \mathrm{p}<0.001)$, but where the correlation between depth and temperature was found to be non-significant $(\mathrm{r}=-0.009$, $p>0.05$ ). Therefore only temperature and depth, along with the sediment class indicator variable, were considered when developing the regression quantile model for sole egg density based on data from all 4 months combined. All 3 variables were found to be significant $(\mathrm{p}<0.05)$ for the 50th, 83rd and 84th quantiles, with the indicator variable strongly significant $(p<0.01)$ for all quantiles except the 99th. Fig. 5 shows the quantile planes for both sediment classes at the 50th and 84th quantiles. In all cases sole egg density was found to decrease with depth and temperature, with a significantly higher density of eggs 

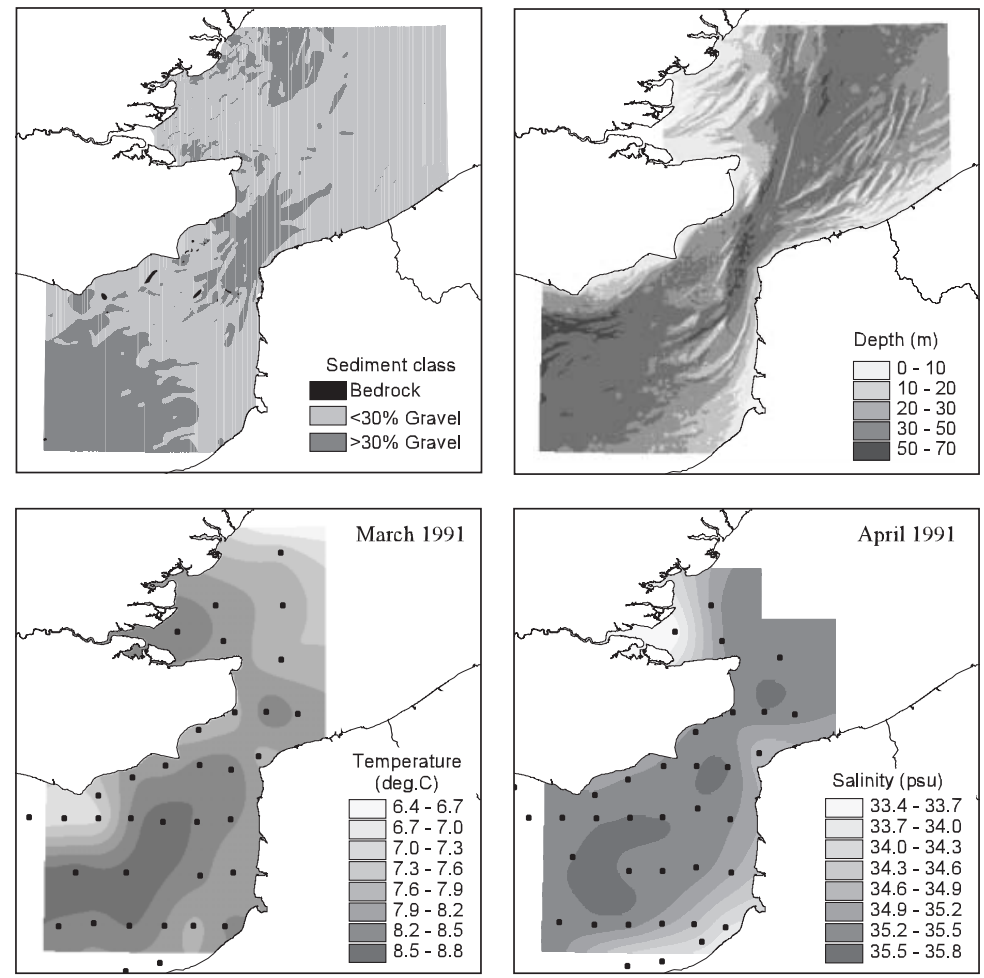

Fig. 4. Examples of the digital environmental maps for the eastern English Channel and southern North Sea used to develop the habitat models. Dots indicate the location of survey stations

also predicted over sediments containing $<30 \%$ gravel content. Parameter estimates for the 84th and 50th quantiles are given in Table 4 .

Fig. 4 shows the digital maps developed for depth and sediment type, and examples of those developed for water column temperature and salinity (i.e. March 1991 temperature, and April 1991 salinity). To minimise interpolation error, the temperature and salinity digital maps were not extrapolated to the north and east beyond a distance equivalent to that separating the survey points at the edge of the survey area. In addition, to ensure spatial coherency, the maps were not extended to the south and west beyond the area covered by the depth and sediment maps. For all months the coastal regions were generally characterised by lower salinity water, and with the exception of March, warmer temperatures. In March a tongue of warmer water was situated offshore in the eastern English Channel, and was approximately 1 to $1.5^{\circ} \mathrm{C}$ warmer than the coastal waters (Fig. 4).
Table 3. Median and 95th percentile density of Stage 1a sole eggs (no. $\mathrm{m}^{-2}$ ) in 1991 for sediment types containing $>30$ and $<30 \%$ gravel

\begin{tabular}{|lcccr|}
\hline \multirow{4}{*}{ March } & \% gravel & $\mathrm{n}$ & Median & 95th \\
\hline \multirow{4}{*}{ April } & $>30$ & 25 & 0.09 & 2.19 \\
& $>30$ & 19 & 1.85 & 11.46 \\
May & $>30$ & 27 & 0.29 & 3.74 \\
& $>30$ & 18 & 7.58 & 39.55 \\
June & $>30$ & 28 & 0 & 6.20 \\
& $>30$ & 26 & 1.98 & 9.28 \\
& $<30$ & 25 & 0 & 0.89 \\
& & & 0.83 & 2.31 \\
\hline
\end{tabular}

Monthly prediction models of egg density developed using both Method A and Method B are shown in Figs 6 \& 7 respectively. The models based on upper estimates clearly predict a higher density of Stage 1a eggs for spatially coincident cells compared to the equivalent models based on central estimates. The model for April 1991 developed using Method A and based on central estimates is not shown, as a 50th regression quantile could not be estimated for this data. The final habitat models developed using both methods are shown in Fig. 8. The difference in spatial coverage between the central model developed using Method A and all other models results from the fact that a prediction model for April 1991 was not used. The output habitat suitability map developed using central estimates from Method A therefore represents the arithmetic mean of 3 input maps (March, May and June 1991 central estimates), as opposed to the other output maps which used prediction maps from all 4 mo as input. The 4 models appeared visually similar in that in all cases the highest suitability scores were located near to the coastline and in association with offshore sandbanks in the outer Thames Estuary. Lowest suit-

Table 4. Parameter estimates and associated significance from rank score tests for central and upper regression quantile models of best fit, for changes in sole egg density (no. $\mathrm{m}^{-2}, \log _{\mathrm{e}}(y+1)$ transformed) according to temperature $\left({ }^{\circ} \mathrm{C}\right)$, depth $(\mathrm{m})$ and sediment type. Models are based on the combined data from March, April, May and June 1991. T $\times$ D is temperature-depth interaction. Significance of the whole model is also given. ${ }^{*} \mathrm{p}<0.05,{ }^{* *} \mathrm{p}<0.01,{ }^{* * *} \mathrm{p}<0.001$

\begin{tabular}{|lcrrrrc|}
\hline Quantile & $\%$ gravel & Constant & Temp & Depth & $\mathrm{T} \times \mathrm{D}$ Whole model \\
\hline 84 & $>30$ & 3.578 & $-0.228^{*}$ & $-0.019^{*}$ & & $* * *$ \\
84 & $<30$ & 4.792 & $-0.228^{*}$ & $-0.019^{*}$ & & $* * *$ \\
50 & $>30$ & 0.892 & $-0.059^{* *}$ & $-0.014^{* *}$ & $0.001^{* *}$ & $* * *$ \\
50 & $<30$ & 3.676 & $-0.257^{* *}$ & $-0.014^{* *}$ & $0.001^{* *}$ & $* * *$ \\
\hline
\end{tabular}



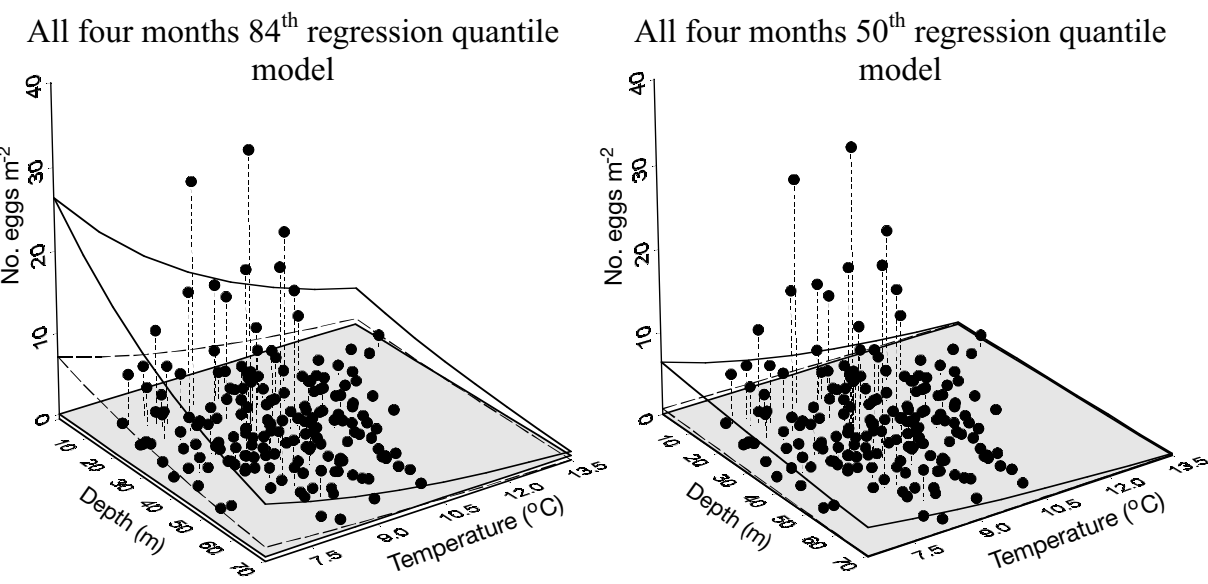

Fig. 5. Scatterplots of Stage 1a sole egg density for all 4 months combined and fitted 84th and 50th regression quantiles based on parameter estimates given in Table 4 . In each plot the 2 planes depict the estimated response to sediments consisting of $<30 \%$ gravel ( - ) and $>30 \%$ gravel (---). Zero egg density is depicted by the shaded plane ability scores were found within the deeper water areas and in association with sediments containing $>30 \%$ gravel.

Fig. 9 shows the distribution of early stage eggs along the French coast of the eastern English Channel during April 1995. Eggs appeared to be aggregated in 2 regions, with higher densities found in the north of the survey network, and also adjacent to the estuaries of the Somme, Canche, and Authie. Patterns of distribution according to temperature, salinity and depth were not as clear, but in general, higher egg densities appeared to be found in shallower waters (Fig. 10). For the test of the models, a positive significant correlation was found between egg density in April 1995 and suitability scores from all 4 habitat suitability models (Table 5). The strength of the relationship was highest for the upper model developed using Method A, and lowest for the Method B central model. The models were also tested by fitting a series of regression quantiles to the egg density in April 1995 and associated habitat suitability scores from the 4 models. Fig. 11 shows that for all 4 models the significant regression quantiles also described a positive relationship between egg density and habitat suitability. In all cases the 25th and 50th quantiles were found to be significant ( $\mathrm{p}<0.05$ ), with the 75 th quantile also significant for the upper model developed using Method A.

Table 5. Spearman's rank correlation coefficients for habitat suitability scores from the 4 models developed using the 1991 egg data, and the density of early stage eggs from the April 1995 test dataset $(\mathrm{n}=39) .{ }^{*} \mathrm{p} \leq 0.05,{ }^{* *} \mathrm{p} \leq 0.01$

\begin{tabular}{|lc|}
\hline Model & No. eggs $\mathrm{m}^{-2}$ \\
\hline Method A upper & $0.425^{* *}$ \\
Method A central & $0.413^{* *}$ \\
Method B upper & $0.419^{* *}$ \\
Method B central & $0.365^{*}$ \\
\hline
\end{tabular}

\section{DISCUSSION}

Depth, temperature, salinity and sediment type were all found to be related to the distribution of Stage 1a sole eggs during at least 1 month in the March to June 1991 spawning season. Temperature was positively related during March only, with low egg densities found in temperatures below $7^{\circ} \mathrm{C}$. Along the east coast of England, Riley (1974) found sole eggs in low densities at water temperatures below $10^{\circ} \mathrm{C}$. Similar findings are reported by Koutsikopoulos \& Lacroix (1992) for the Bay of Biscay where the majority of eggs collected were found at temperatures $>9^{\circ} \mathrm{C}$. The results of this study also suggest that sole spawn when temperatures rise above a certain minimum. However it remains unclear whether a rise in temperature during the early spring acts to trigger spawning, or whether spawning cannot be detected in waters of low temperature due to high natural mortality of sole eggs. Complete mortality has been found to occur if eggs are held at temperatures below $6^{\circ} \mathrm{C}$, with successful full-term incubation only possible at temperatures $>7^{\circ} \mathrm{C}$ (Irvin 1974). In contrast, the regression quantile models developed for May and June suggest a slight decrease in the density of sole eggs with temperature. The range of temperatures encountered during these 2 months $\left(8.8\right.$ to $\left.13.3^{\circ} \mathrm{C}\right)$ would not be expected to elicit any appreciable differences in spawning activity, and indeed the response patterns during these 2 months are not as clearly defined in comparison to that seen for March. For the model developed from all monthly data combined the predicted decrease in density as temperature increases may simply reflect the decline in spawning activity from the peak in April through to May and June.

A negative relationship between egg density and depth was found for all 4 months, confirming the preference displayed by the sole to spawn in the shallow water regions of the eastern English Channel and 

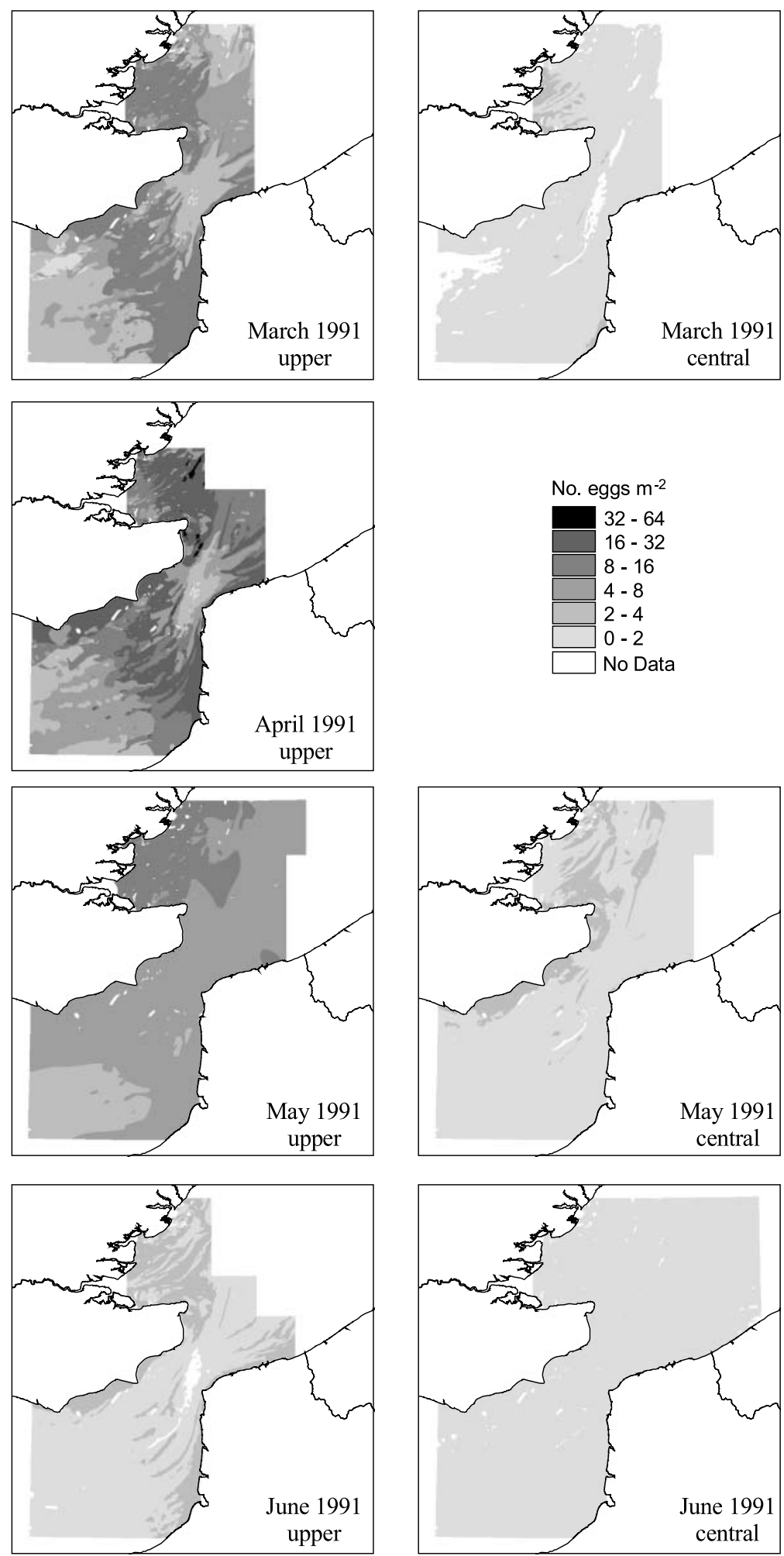

Fig. 6. Predicted density of Stage 1a sole eggs developed from both upper (left) and central (right) estimates from Method A in March, April, May and June 1991 for the eastern English Channel and southern North Sea. The central model for April is not presented because a 50th regression quantile could not be estimated for these data southern North Sea (Borremans 1987, Land 1991, ICES 1992). Indeed if the effect of temperature is removed from the model based on all data combined, which could simply reflect temporal differences in spawning activity, then depth, along with sediment type, would seem to be a principal determinant of spawning activity in the eastern English Channel. Larval transfer to the inshore nursery grounds would be facilitated by this behavioural mechanism. However, local hydrodynamics are also thought to contribute towards larval transport and spawning success, particularly where sole are found to inhabit regions characterised by deeper waters, such as the Bay of Biscay (Koutsikopoulos \& Lacroix 1992), and the Bristol Channel (Horwood 1993, Symonds \& Rogers 1995). Similar mechanisms may also be in place in the eastern English Channel (Grioche 1998).

A relationship between egg density and salinity is suggested during April and May, although the responses predicted in each month are in direct contrast. The strong negative relationship between salinity and egg density in May suggests that a preference exists for the lower salinity water found along both the English and French inshore regions, whilst a weaker, positive relationship suggests the converse is true in April. As sole are capable of tolerating a much wider salinity range than that encountered within the spatial limits of the survey (Marchand 1991), and as temperature, depth, proximity to riverine outflows and distance to the shore could all be considered as intercorrelated with salinity, it is difficult to untangle the actual environmental cues the sole might be responding to. Consequently, salinity may not be acting as a limiting factor to spawning activity as suggested by the model, but may instead represent the best predictor to describe the distribution of sole eggs in May.

A clear relationship was found between egg density and sediment type, with consistently higher densities found over sediment containing $<30 \%$ gravel. The preference for sandy and finer-grained sediments by both juvenile and adult sole 

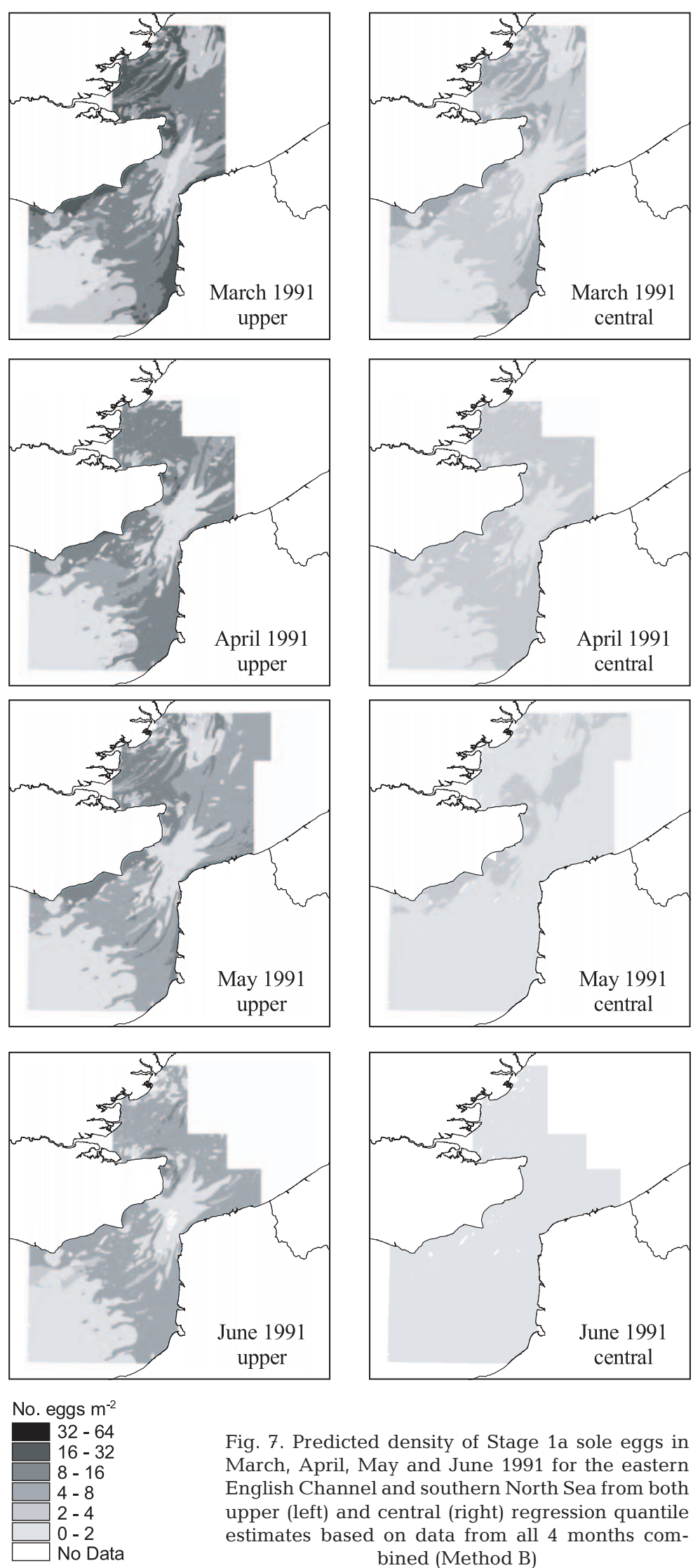

Fig. 7. Predicted density of Stage 1a sole eggs in March, April, May and June 1991 for the eastern English Channel and southern North Sea from both upper (left) and central (right) regression quantile estimates based on data from all 4 months combined (Method B) is well documented (Dorel et al. 1991, Rogers 1992, Koutsikopoulos \& Lacroix 1992, Horwood 1993, Kaiser et al. 1999). Whilst spawning itself is thought to occur either in midwater or at the surface (Horwood 1993), sole bury themselves into sandy substratum during the day and feed during the night on a variety of infaunal invertebrates associated with finer-grained sediments (Lagardère 1987, Molinero \& Flos 1991). Whilst sandy sediments cover most of the eastern English Channel and southern North Sea, spawning adults would not be expected wherever this sediment type occurs, as would appear to be suggested by the maps. An important factor contributing to this is that habitat definition can only be defined at the spatial resolution of the underlying data, and clearly the broad categorisation of sediments containing $<30 \%$ gravel will in reality consist of a gradation of sediment types, interspersed by patches of varying structural complexity, which are difficult to resolve spatially. In addition, the strong tidal currents that characterise the region will undoubtedly lead to temporal differences in the composition of the seabed sediments and possibly even to localised variations in depth. This cannot be accounted for with static maps of depth and sediment type, particularly where the maps represent compilations and interpretations of data collected over long time periods, as is the case for the paper charts and maps used in this study. Within this spatial and temporal heterogeneity, sole may also only occupy a limited range of the habitat variable, depending on the population size, with a wider range occupied with increasing population density (Gibson 1994). Consequently, both heterogeneity of habitat type, and variability of habitat use will all contribute substantially towards the variability inherent to plots of species-habitat relationships (Rogers 1992, Thomson et al. 1996), and to the spatial heterogeneity commonly exhibited in populations and communities (Legendre \& Fortin 1989). By modelling the upper limits of the density of sole eggs within both the broad categories of sediment type and the continuous variables of temperature, salinity and depth, the relative suitability of the habitat is not underestimated, or at least is underestimated to a lesser degree than estimates of central tendency. 

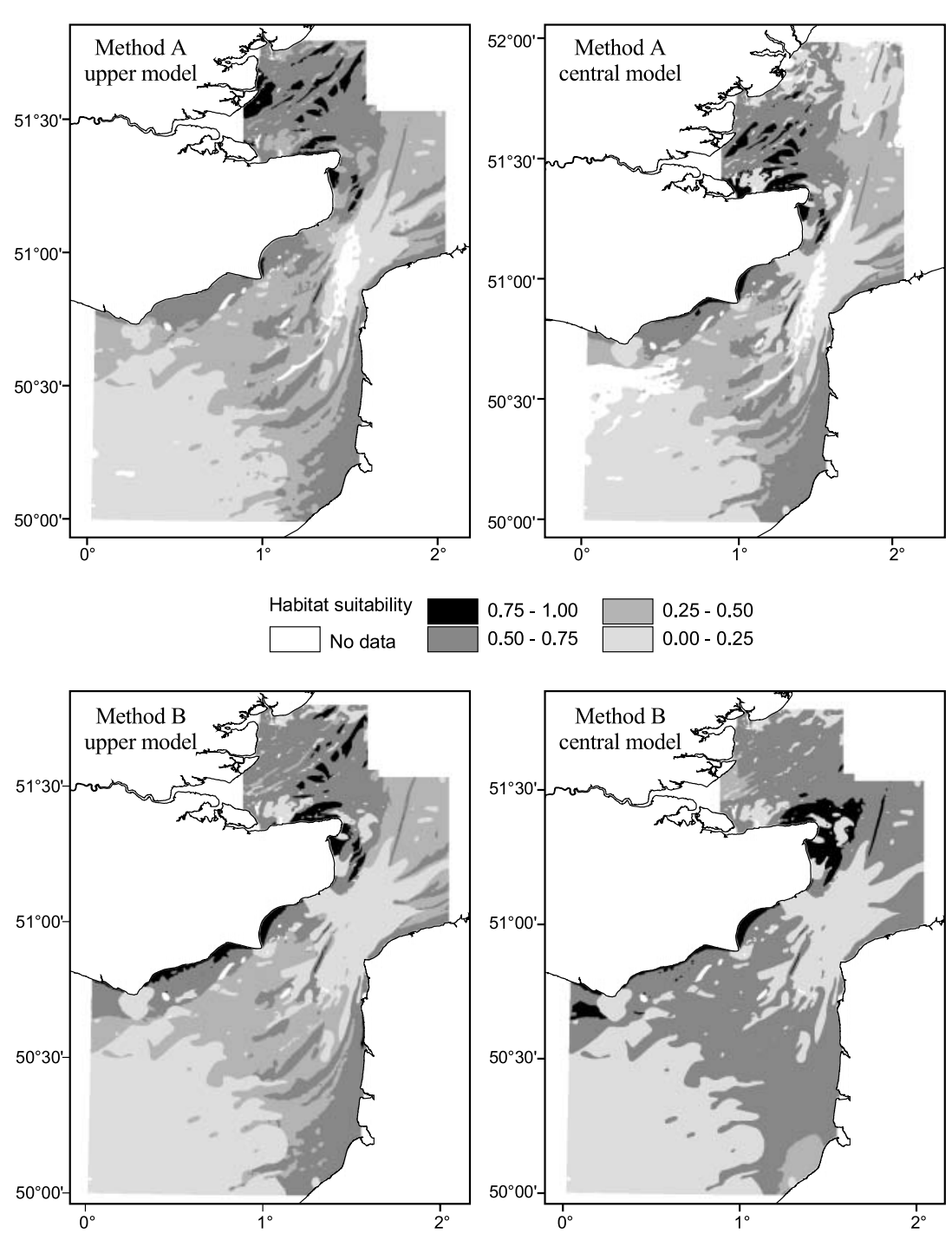

Fig. 8. Spawning habitat suitability models for the sole in the eastern English Channel and southern North Sea for the 1991 spawning season, developed from central and upper estimates and using either Method A or B

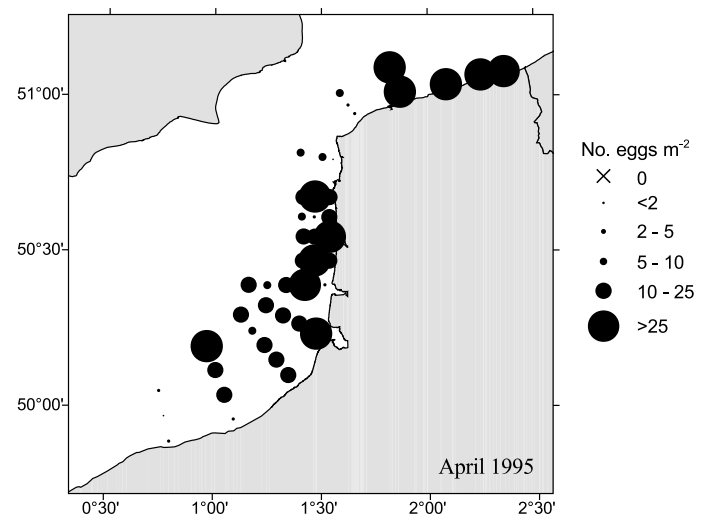

Fig. 9. Distribution of early stage sole eggs along the French coast of the eastern English Channel during April 1995, used to test the final habitat suitability models developed from the 1991 data

appeared to be marginal at first. This was caused by the conversion of habitat suitability to a relative scale, which had the effect of damping any potential differences between the linear model estimates. Method A allowed for a closer examination of the responses within each month, but by modelling the response to sediment type and the continuous variables separately, the assumption is made that the habitat variables are selected independently of each other. This issue was resolved by Method B which also eliminated the need for arbitrary decision making such as choosing an appropriate percentile within the sediment classes to represent the upper limits of the response. One immediately apparent difference between the predicted maps of spawning

Considering the 2 methodologies, advantages and disadvantages can be attributed to each. Both models predicted different levels of spawning habitat suitability, although visual differences between the models activity is that Method B appears to predict similar levels of spawning activity for each month, in contrast to Method A, where differences between months are more noticeable. The reason is easily understood given
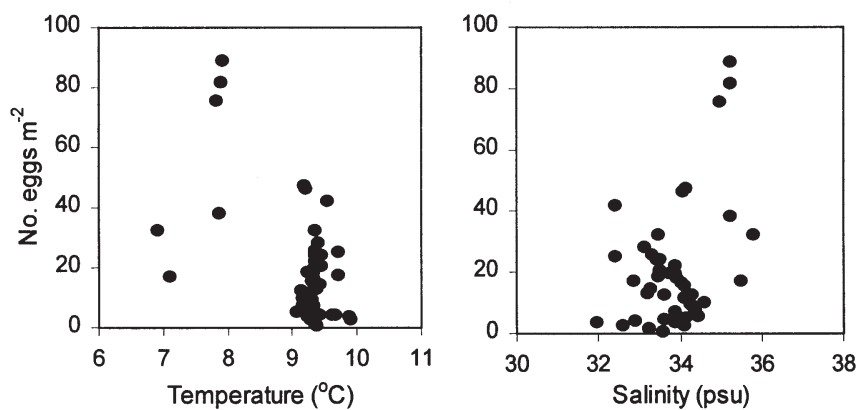

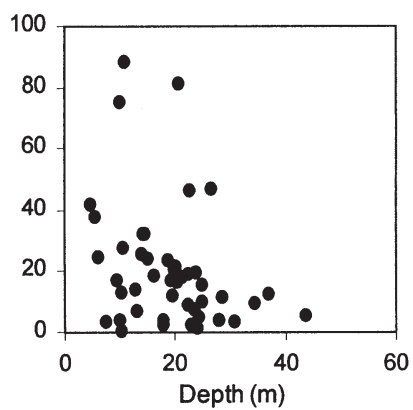

Fig. 10. Scatterplots of early stage egg density against average water column temperature, salinity, and depth, from data collected along the French coast of the eastern English Channel during April 1995 

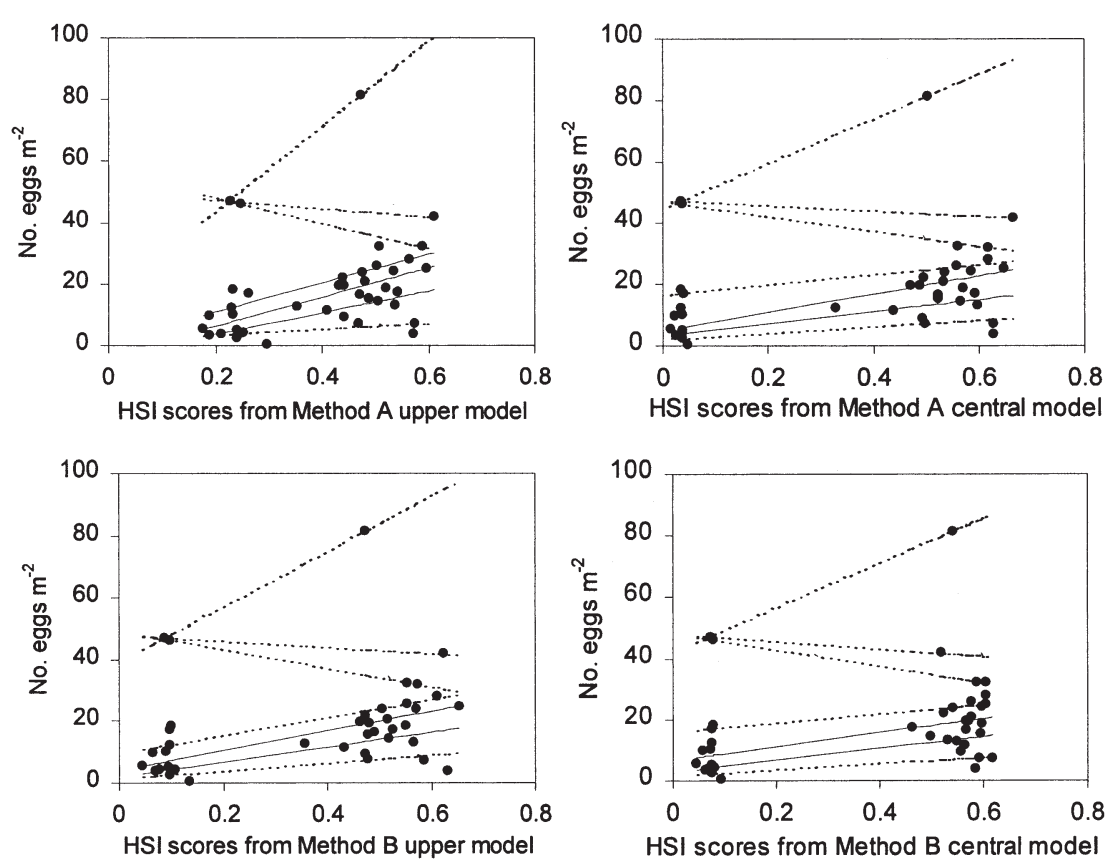

Fig. 11. Selected regression quantiles (10th, 25th, 50th, 75th, 90th, 95th, and 99th) fitted to the April 1995 sole egg data and scores from the spawning habitat suitability models developed using the 1991 Stage 1a egg data. (-,----$)$, regression quantiles with significant and non-significant slope coefficients respectively $(p<0.05$, asymptotic rank score test). All 25th and 50th quantiles are significant, with the 75th quantile significant for the Method A upper model only

the way in which the 2 methods model the spawning response to monthly variations in the environmental variables. Method A relied on the estimated egg density within each sediment type as input, which gave relatively varied estimates of density for each month: density was predicted to be high in April and low in June. Method B in contrast, gave similar predictions, as the same regression estimates were used for each month. The only change in density that could occur using Method B came from the monthly difference in temperature.

The statistical properties of regression quantiles offer important advantages over least-squares estimates. Most notably, the assumptions of least-squares regression are violated if the variability in the species response increases or decreases with changes in the independent variable. Unfortunately this is a common problem with ecological data. For example, Terrell et al. (1996) evaluated 35 datasets of stream fish standing stock and found that 13 violated the assumption of homoscedastic error variance required for leastsquares regression. Regression quantiles are also capable of modelling variability in the response distribution through the estimation of a range of quantiles. In doing so, regression quantiles are able to detect the effects of limiting factors in some upper quantiles that may not be directly evident through an examination of central estimates. A clear example is given here, when during April 1991 the 50th quantile could not be estimated, whereas both depth and salinity were found to be significant explanatory variables at the 75th quantile. Regression quantile estimates have also been found to be more resistant to the influence of outlying values of the dependent variable (Scharf et al. 1998), as the statistical properties of the estimates rely on the sign of the dependent variable, rather than the magnitude.

The models of spawning habitat suitability for the sole Solea solea developed in this study are far from definitive, particularly as they rely purely on the distribution of sole eggs from a single spawning season. Annual variations in the environmental variables or in the abundance of sole eggs, could potentially lead to different models of spawning habitat suitability. Furthermore, the UKHO and BGS maps of depth and sediment type used in this study were developed from data collected over a number of years, and so may not accurately represent conditions in 1991. Unfortunately, in the absence of additional data, it is impossible to evaluate the robustness of the habitat suitability models in predicting the spatial distribution of sole egg density when environmental conditions differ from that seen in 1991. However, the models do represent a methodology to achieve more realistic definitions and maps of potential fish habitat when only a limited number of habitat factors are available. Whilst this has a tendency to oversimplify a complex system (Rogers 1992), habitat models that attempt to incorporate an increasing number of factors may not necessarily achieve greater predictive power. It has also been argued that functional relationships based on central estimates of the biological response contradict the ecological theory of limiting factors (Thomson et al. 1996). Therefore techniques relying on such estimates do little to progress our understanding of the way in which biological responses are limited by those environmental variables that define habitat spatial location and suitability. Langton \& Auster (1999) call for research to be 'directed at discovering and describing the underlying processes and mechanisms that explain patterns we see in natural systems'. For ecological investigations, quantile regression represents a valuable statistical tool that can help to achieve this aim, by providing a more flexible approach to regression analysis and model fitting. 
Acknowledgements. This study was supported by a European Commission INTERREG grant (GOSE 97/C8/03). The authors would like to offer sincere thanks to Brian S. Cade from the Midcontinent Ecological Science Centre, US Geological Survey, for considerable help and support with the regression quantile routine implemented within BLOSSOM, and for valuable comments on an earlier draft. Brian S. Cade, Jon D. Richards and the US Geological Survey are also gratefully acknowledged for the development and distribution of the BLOSSOM software program. Thanks also to 3 anonymous referees for critically reviewing an earlier draft of the manuscript, to Ray Godfrey from Canterbury Christ Church University College, and to the UK Centre for Environment, Fisheries and Aquaculture Science, the British Geological Survey, and the UK Hydrographic Office for providing data in support of this study. This work is based partly on data provided with the support of the UK Economic and Social Research Council and Joint Information Systems Committee and uses boundary material which is copyright of The Crown and the ED-LINE Consortium. Digital depth map reproduced from Admiralty Chart nos. 1406, 1607, 1975, 2449, 2451 and 2656 by permission of The Controller of Her Majesty's Stationery Office, the Port of London Authority, and the hydrographic offices of Belgium, France, the Netherlands and the United Kingdom. Sea-bed sediments digital map reproduced from British Geological Survey UTM map sheets (Dungeness to Boulogne, Thames, and Ostend) at the original scale of 1:250 000. Licence 99/80, British Geological Survey. ONERC. All rights reserved. England coastal boundary data, OCrown and ED-LINE

\section{LITERATURE CITED}

Borremans C (1987) North Sea spawning grounds of the sole (Solea solea) located from the 1984 Belgian plankton survey. In: Kullander SO, Fernholm B (eds) Proc V Congr Eur Ichthyol, Swedish Museum of Natural History, Stockholm, p 187-191

Brown SK, Buja KR, Jury SH, Monaco ME, Banner A (2000) Habitat suitability index models for eight fish and invertebrate species in Casco and Sheepscot Bays, Maine. N Am J Fish Manage 20:408-435

Cade BS, Richards JD (2000) User manual for BLOSSOM statistical software. Midcontinent Ecological Science Center, US Geological Survey, Fort Collins, CO

Cade BS, Terrell JW, Schroeder RL (1999) Estimating effects of limiting factors with regression quantiles. Ecology 80: 311-323

Christensen JD, Battista TA, Monaco ME, Klein CJ (1997) Habitat suitability index modeling and GIS technology to support habitat management: Pensacola Bay, Florida case study. Technical report to the US Environmental Protection Agency, Gulf of Mexico Program, NOAA/NOS Strategic Environmental Assessments Division. Silver Spring, MD

Clark RD, Minello TJ, Christensen JD, Caldwell PA, Monaco ME, Matthews GA (1999) Modeling nekton habitat use in Galveston Bay, Texas: an approach to define essential fish habitat (EFH). NOAA/NOS Biogeography Program, Silver Spring, Maryland, and NMFS, Galveston, TX

D'Amours D (1993) The distribution of cod (Gadus morhua) in relation to temperature and oxygen level in the Gulf of St. Lawrence. Fish Oceanogr 2:24-29

Dorel D, Koutsikopoulos C, Desauney Y, Marchand J (1991) Seasonal distribution of young sole (Solea solea L) in the nursery ground of the Bay of Vilaine (northern Bay of Biscay). Neth J Sea Res 27:297-306
Folk RL (1954) The distinction between grain size and mineral composition in sedimentary-rock nomenclature. J Geol 62: 344-359

Gibson RN (1994) Impact of habitat quality and quantity on the recruitment of juvenile flatfishes. Neth J Sea Res 32: 191-206

Grioche A (1998) Dynamique de l'écophase ichtyoplanctonique en Manche orientale et sud Mer du Nord. Approche multispécifique et description de deux espèces cibles: Solea solea (L) et Pleuronectes flesus (L). PhD thesis, Université du Littoral—Côte d'Opale, Dunkerque

Grioche A, Koubbi P, Harlay X (1999) Spatial patterns of ichthyoplankton assemblages along the eastern English Channel French coast during Spring 1995. Estuar Coast Shelf Sci 49:141-152

Hall SJ (1998) The effects of fishing on marine ecosystems and communities. Blackwell Science, Oxford

Horwood J (1993) The Bristol Channel sole (Solea solea L): a fisheries case study. In: Blaxter JHS, Southward AJ (eds) Advances in marine biology. Academic Press, London, p 215-367

ICES (International Council for the Exploration of the Sea) (1992) Report of the study group on the fecundity of sole and plaice in sub-areas IV, VII and VIII. ICES Counc Meet Pap 1992/G:16

Irvin DN (1974) Temperature tolerance of early developmental stages of Dover sole, Solea solea (L). In: Blaxter JHS (ed) The early life history of fish. Springer-Verlag, Berlin, p 449-463

Kaiser MJ, Rogers SI, Ellis JR (1999) Importance of benthic habitat complexity for demersal fish assemblages. In: Benaka LR (ed) Fish habitat: essential fish habitat and rehabilitation. American Fisheries Society, Symposium 22, Bethesda, MD, p 212-223

Koenker R, Bassett G (1978) Regression quantiles. Econometrica 50:43-61

Koenker R, d'Orey V (1994) A remark on algorithm AS229: computing dual regression quantiles and regression rank scores. Appl Stat 43:410-414

Koutsikopoulos C, Lacroix N (1992) Distribution and abundance of sole (Solea solea L) eggs and larvae in the Bay of Biscay between 1986 and 1989. Neth J Sea Res 29:81-91

Lagardère JP (1987) Feeding ecology and daily food consumption of common sole, Solea vulgaris Quensel, juveniles on the French Atlantic coast. J Fish Biol 30:91-104

Land MA van der (1991) Distribution of flatfish eggs in the 1989 egg surveys in the southeastern North Sea, and mortality of plaice and sole eggs. Neth J Sea Res 27:277-286

Langton RW, Auster PJ (1999) Managing essential fish habitat: what are the next steps? Fisheries 24:30-31

Legendre P, Fortin MJ (1989) Spatial pattern and ecological analysis. Vegetatio 80:107-138

Marchand J (1991) The influence of environmental conditions on settlement, distribution and growth of 0-group sole (Solea solea L) in a macrotidal estuary (Vilaine, France). Neth J Sea Res 27:307-316

Molinero A, Flos R (1991) Influence of sex and age on the feeding habits of the common sole Solea solea. Mar Biol 111:493-501

Montgomery DC, Peck EA (1992) Introduction to linear regression analysis. John Wiley and Sons, New York

Murawski SA, Finn JT (1988) Biological basis for mixed-species fisheries: species co-distribution in relation to environmental and biotic variables. Can J Fish Aquat Sci 45: 1720-1735

NMFS (National Marine Fisheries Service) (1999) Ecosystembased fishery management. A Report to Congress by the 
Ecosystem Principles Advisory Panel. US National Marine Fisheries Service, Washington, DC

Norcross BL, Blanchard A, Holladay BA (1999) Comparison of models for defining nearshore flatfish nursery areas in Alaskan waters. Fish Oceanogr 8:50-67

Riley JD (1974) The distribution and mortality of sole eggs (Solea solea L) in inshore areas. In: Blaxter JHS (ed) The early life history of fish. Springer-Verlag, Berlin, p 39-52

Rogers SI (1992) Environmental factors affecting the distribution of sole (Solea solea L) within a nursery area. Neth J Sea Res 29:153-161

Rubec PJ, Bexley JCW, Norris H, Coyne MS, Monaco ME, Smith SG, Ault JS (1999) Suitability modeling to delineate habitat essential to sustainable fisheries. In: Benaka L (ed) Fish habitat: essential fish habitat and rehabilitation. American Fisheries Society, Symposium 22, Bethesda, MD, p 108-133

Scharf FS, Juanes F, Sutherland M (1998) Inferring ecological relationships from the edges of scatter diagrams: comparison of regression techniques. Ecology 79:448-460

Schmidt K (1998) Ecology's catch of the day. Science 281: 192-193

Scott JS (1982) Selection of bottom type by groundfishes of the Scotian Shelf. Can J Fish Aquat Sci 39:943-947

Editorial responsibility: Otto Kinne (Editor),

Oldendorf/Luhe, Germany
Swain DP, Kramer DL (1995) Annual variation in temperature selection by Atlantic cod Gadus morhua in the southern Gulf of St. Lawrence, Canada, and its relation to population size. Mar Ecol Prog Ser 116:11-23

Symonds DJ, Rogers SI (1995) The influence of spawning and nursery grounds on the distribution of sole Solea solea (L) in the Irish Sea, Bristol Channel and adjacent areas. J Exp Mar Biol Ecol 190:243-261

Tegner MJ, Dayton PK (1999) Ecosystem effects of fishing. Trends Ecol Evol 14:261-262

Terrell JW, Carpenter J (1997) Selected habitat suitability index model evaluations. Information and Technology Report, USGS/BRD/ITR--1997--0005, US Department of the Interior, US Geological Survey. Washington, DC

Terrell JW, Cade BS, Carpenter J, Thompson JM (1996) Modeling stream fish habitat limitations from wedge-shaped patterns of variation in standing stock. Trans Am Fish Soc 125:104-117

Thomson JD, Weiblen G, Thomson BA, Alfaro S, Legendre P (1996) Untangling multiple factors in spatial distributions: lilies, gophers and rocks. Ecology 77:1698-1715

USFWS (US Fish and Wildlife Service) (1980) Habitat evaluation procedures. ESM report 102(2-80) US Department of the Interior, Washington, DC

Submitted: September 4, 2000; Accepted: April 5, 2001 Proofs received from author(s): December 10, 2001 